\title{
A Nonlinear Optical Polyurethane Functionalized with a Heteroaromatic Thiophene Ring Having a Tricyanovinyl Group
}

\author{
Han Young Woo, Hong-Ku SHIM, ${ }^{\dagger}$ and Kwang-Sup LeE, ${ }^{* \dagger}$ \\ Department of Chemistry, Korea Advanced Institute of Science and Technology, \\ Taejon 305-701, Korea \\ * Department of Polymer Science and Engineering, Hannam University, \\ Taejon 306-791, Korea
}

(Received January 8, 1999)

\begin{abstract}
A new functionalized polyurethane structure with a thiophene ring having a tricyanovinyl group in the polymer side chain was synthesized. The molecular weight of the final polymer was determined to be $M_{n}=12000$ and $M_{w} / M_{n}=2.04$. The resulting polymer was soluble in $N$-methylpyrrolidinone and could be processed into good optical quality films by spin casting at $\mathrm{ca} .100^{\circ} \mathrm{C}$. It showed no weight loss up to $266^{\circ} \mathrm{C}$ in the thermogravimetric analysis and a definite glass transition at $176^{\circ} \mathrm{C}$. The second-order nonlinear optical coefficient, $d_{33}$, was determined to be $51 \mathrm{pm} \mathrm{V}^{-1}$ from measuring the second harmonic generation (SHG) for a thin polymer film after poling treatment. The outstanding orientational stability of the aligned chromophores was observed up to about $150^{\circ} \mathrm{C}$, which originated from the rigid polymer backbone and the stabilizing function of the hydrogen bridges formed between the neighboring polyurethane chains.

KEY WORDS Nonlinear Optics / Polyurethane / Thiophene Ring / Tricyanovinyl Group / Second Harmonic Generation / Thermal Stability /
\end{abstract}

In recent years there has been a considerable research effort in the development of nonlinear optical (NLO) polymers for applications in optical signal processing, optical computing, and telecommunications. ${ }^{1,2}$ To realize practical applications, first of all the optical nonlinearity and temporal stability of the system must be improved. Various NLO chromophores which have high optical nonlinearity, thermal and photochemical stability were incorporated into many types of polymers such as high $T_{\mathrm{g}}$ polyimides, ${ }^{3-7}$ polyurethanes, ${ }^{8,9}$ crosslinkable polymers, etc. ${ }^{10-12}$

During the past decade, several electron-donor and -acceptor substituted conjugated compounds such as functionalized benzenes, biphenyls, stilbenes, acetylenes, Schiff bases and azobenzenes have been developed for second-order NLO applications. ${ }^{13-16}$ However, these benzenoid structures suffered from relatively low nonlinearity, limited solubility, and difficulty in the synthesis of extended conjugated compounds. ${ }^{17}$ So an alternate approach to the design of superior NLO chromophores with electron-rich five-membered heteroaromatics, such as thiophene, as the conjugating moieties between donor and acceptor substituents has been tried. ${ }^{17-19}$ Since thiophene has a lower delocalization energy than that of benzene, ${ }^{20}$ it can offer more effective conjugation than that of benzene in donor-acceptor compounds, resulting in better optical nonlinearity. The previous works by Alex K.-Y. Jen et al. presented $\beta \mu$ values of thiophene-based chromophores with those of benzenoid ones with same structure obtained using electric field induced second harmonic generation (EFISH). ${ }^{17,18}$

We incorporated the chromophore containing thiophene into a polyurethane backbone, expecting an improvement in optical nonlinearity and stability relative to reported cases. In addition, the reason why we chose polyurethane as a matrix was that an extensive formation

\footnotetext{
$\dagger$ To whom correspondence should be addressed.
}

of hydrogen bonds between the urethane linkage was expected to increase the rigidity of the matrix and to prevent randomization of the oriented NLO chromophore dipoles. The physically crosslinked system via hydrogen bridges has the advantage of homogeneity and good processibility relative to the chemically crosslinked system, which suffers from significant optical losses and poor processibility.

In this report, we present the synthesis of a new polyurethane structure functionalized with a thiophene chromophore with a tricyanovinyl group. We discuss the chemical and physical characterization and the details of its optical second-order NLO activity in terms of electric poling and thermal stability.

\section{EXPERIMENTAL}

\section{Materials}

$N, N$-Dimethylformamide (DMF) (Junsei) was purified by vacuum distillation over phosphorous pentoxide and dried further over $4 \AA$ molecular sieves. Tetrahydrofuran (THF) was purified by distillation over sodium chips and benzophenone. 4,4'-Diisocyanato-3,3'-dimethoxydiphenyl (PFALTZ \& BAUER, inc.) was purified by recrystallization from methylene chloride. All other solvents and reagents were of analytical-grade quality, purchased commercially and used as received unless otherwise stated.

\section{Monomer Synthesis}

2-Bromomethylthiophene (1). To a mixture of 2methylthiophene $(10 \mathrm{~g}, 101.9 \mathrm{mmol})$ and $N$-bromosuccinimide $(16.3 \mathrm{~g}, 91.6 \mathrm{mmol})$ in $120 \mathrm{~mL}$ of carbon tetrachloride was added a catalytic amount of benzoyl peroxide $(0.4 \mathrm{~g})$. The mixture was heated at $75^{\circ} \mathrm{C}$ for $2 \mathrm{~h}$ under nitrogen and then cooled to room temperature. The succinimide produced was filtered out and the resulting solution was extracted with methylene chloride. The organic layer was washed with a $3 \mathrm{~N}$ aqueous sodium 
hydroxide solution and concentrated under reduced pressure. The crude reaction product was purified by distillation under reduced pressure to afford compound 1 with the yield of $13.4 \mathrm{~g}(73.9 \%)$. bp: $40^{\circ} \mathrm{C} / 3 \mathrm{mmHg} .{ }^{1} \mathrm{H}$ NMR $\left(\mathrm{CDCl}_{3}, \mathrm{ppm}\right): \delta 7.31(\mathrm{~m}, 1 \mathrm{H}, \mathrm{Ar} \mathrm{H}), 7.10(\mathrm{~m}$, $1 \mathrm{H}, \mathrm{Ar} \mathrm{H}), 6.93(\mathrm{~m}, 1 \mathrm{H}, \mathrm{ArH}), 4.75$ (s, 2H, $\mathrm{ArCH} \mathrm{H}_{2} \mathrm{Br}$ ).

Diethyl Thiophene-2-ylmethylphosphonate (2). The mixture of 2-bromomethylthiophene $(10 \mathrm{~g}, 56.5 \mathrm{mmol})$ and triethyl phosphite $(10.3 \mathrm{~g}, 62.0 \mathrm{mmol})$ was heated at $80^{\circ} \mathrm{C}$ for $12 \mathrm{~h}$. The distilled ethyl bromide was removed. The product was obtained by distillation under reduced pressure with the yield of $12.5 \mathrm{~g}(94.7 \%)$. bp: $100-$ $110^{\circ} \mathrm{C} / 3 \mathrm{mmHg} .{ }^{1} \mathrm{H}$ NMR $\left(\mathrm{CDCl}_{3}, \mathrm{ppm}\right): \delta 6.96(\mathrm{~m}$, $1 \mathrm{H}, \operatorname{Ar} \mathrm{H}), 6.75(\mathrm{~m}, 2 \mathrm{H}, \operatorname{Ar} \mathrm{H}), 3.85(\mathrm{~m}, 4 \mathrm{H}$, $-\mathrm{OCH}_{2} \mathrm{CH}_{3}$ ), 3.15 (d, $\left.\mathrm{J}=20 \mathrm{~Hz}, 2 \mathrm{H}, \mathrm{ArCH}{ }_{2} \mathrm{PO}-\right), 1.06$ (t, $\left.J=6 \mathrm{~Hz}, \quad 6 \mathrm{H}, \quad-\mathrm{OCH}_{2} \mathrm{CH}_{3}\right)$. Anal. Calcd for $\mathrm{C}_{9} \mathrm{H}_{15} \mathrm{O}_{3}$ PS: C, 61.57; H, 6.47; S, 13.69. Found: C, 61.49; $\mathrm{H}, 6.51 ; \mathrm{S}, 13.63$.

$[N, N$-Bis[2-(acetyloxy)ethyl $]$ amino $]$ benzene (3). To a solution of $30.0 \mathrm{~g}(0.17 \mathrm{~mol})$ of $N, N$-bis(2-hydroxyethyl)aminobenzene in $200 \mathrm{~mL}$ of methylene chloride was added $40.6 \mathrm{~g}(0.40 \mathrm{~mol})$ of acetic anhydride. Then $40.2 \mathrm{~g}$ of triethylamine $(0.40 \mathrm{~mol})$ was added dropwise to the above solution in an ice bath and stirred at room temperature for $3 \mathrm{~h}$. The reaction mixture was washed with water several times. The organic layer was dried with anhydrous magnesium sulfate and then concentrated. The product was purified by distillation under reduced pressure to give compound $\mathbf{3}$ as a yellow viscous oil with the yield of $36.4 \mathrm{~g}(83.0 \%)$. bp: $182^{\circ} \mathrm{C} / 1.2 \mathrm{mmHg}$, ${ }^{1} \mathrm{H}$ NMR $\left(\mathrm{CDCl}_{3}, \mathrm{ppm}\right): \delta 7.22(\mathrm{~m}, 2 \mathrm{H}, \mathrm{Ar} \mathrm{H}), 6.75(\mathrm{~m}$, $3 \mathrm{H}, \mathrm{Ar} \mathrm{H}), 4.22\left(\mathrm{t}, \mathrm{J}=6 \mathrm{~Hz}, 4 \mathrm{H},-\mathrm{NCH}_{2} \mathrm{CH}_{2} \mathrm{OAc}\right), 3.60$ (t, $\left.J=6 \mathrm{~Hz}, 4 \mathrm{H},-\mathrm{NCH}_{2} \mathrm{CH}_{2} \mathrm{OAc}\right), 2.04\left(\mathrm{~s}, 6 \mathrm{H},-\mathrm{COCH}_{3}\right)$. Anal. Calcd for $\mathrm{C}_{14} \mathrm{H}_{19} \mathrm{NO}_{4}$ : C, 63.38; H, 7.22; N, 5.28. Found: C, 63.00; H, 7.27; N, 5.25.

$4-[N, N-B i s[2-($ acetyloxy $)$ ethyl $]$ amino $]$ benzaldehyde (4). Anhydrous DMF ( $40 \mathrm{~mL})$ was placed in a two-necked $250 \mathrm{~mL}$ flask and cooled in an ice bath. $25.4 \mathrm{~g}(0.17 \mathrm{~mol})$ of phosphorous oxychloride was then added, dropwise, with stirring. After $30 \mathrm{~min}, 40 \mathrm{~g}(0.15 \mathrm{~mol})$ of compound 3 was added to the flask. The solution was heated at $90^{\circ} \mathrm{C}$ for $2 \mathrm{~h}$. The reaction mixture was then cooled, poured into crushed ice in a beaker, and neutralized to $\mathrm{pH} 6-8$ by an addition of saturated aqueous sodium hydroxide solution. The crude product was extracted with ethyl acetate. The extracts were washed with water, dried with anhydrous magnesium sulfate, and then concentrated. The resulting crude solid was washed in a small amount of methanol to yield $42.2 \mathrm{~g}(96.0 \%)$ of the yellow solid product. $\mathrm{mp}: 60^{\circ} \mathrm{C} .{ }^{1} \mathrm{H} \mathrm{NMR}\left(\mathrm{CDCl}_{3}, \mathrm{ppm}\right)$ : $\delta 9.71(\mathrm{~s}, 1 \mathrm{H},-C H O) 7.70(\mathrm{~d}, J=9 \mathrm{~Hz}, 2 \mathrm{H}, \mathrm{Ar} \mathrm{H}), 6.77$ $(\mathrm{d}, J=9 \mathrm{~Hz}, 2 \mathrm{H}, \mathrm{Ar} \mathrm{H}), 4.23(\mathrm{t}, J=6 \mathrm{~Hz}, 4 \mathrm{H}$, $\left.-\mathrm{NCH}_{2} \mathrm{CH}_{2} \mathrm{OAc}\right), 3.68\left(\mathrm{t}, J=6 \mathrm{~Hz}, 4 \mathrm{H},-\mathrm{NCH}_{2} \mathrm{CH}_{2}-\right.$ OAc) $2.00\left(\mathrm{~s}, 6 \mathrm{H},-\mathrm{COCH}_{3}\right)$. Anal. Calcd for $\mathrm{C}_{15} \mathrm{H}_{19} \mathrm{NO}_{5}$ : C, 61.42; H, 6.53; N, 4.78. Found: C, 61.11; $\mathrm{H}, 6.61 ; \mathrm{N}, 4.68$.

$N, N$-Bis(2-hydroxyethyl)-4-[2-(thiophene-2-yl)vinyl]aniline (5). To a solution of compound $4(8.0 \mathrm{~g}$, $27.2 \mathrm{mmol})$ and potassium $t$-butoxide $(3.7 \mathrm{~g}, 33.0 \mathrm{mmol})$ in $70 \mathrm{~mL}$ of anhydrous THF was added dropwise compound $2(6.4 \mathrm{~g}, 27.2 \mathrm{mmol})$ in $20 \mathrm{~mL}$ of anhydrous THF. If compound $\mathbf{2}$ is added rapidly, a coagulation of the reactants may happen. The solution was heated at ca. $70^{\circ} \mathrm{C}$ for $24 \mathrm{~h}$ under nitrogen atmosphere. The reaction mixture was cooled to room temperature and extracted with methylene chloride. The organic layer was concentrated under reduced pressure and $150 \mathrm{~mL}$ of methanol was added. And then $4 \mathrm{~g}$ of sodium hydroxide in $30 \mathrm{~mL}$ of water was added to the above solution and hydrolyzed at $c a .90^{\circ} \mathrm{C}$ for $3 \mathrm{~h}$. When the solution was cooled to room temperature, the yellow solid precipitated. The concentration of this solution gave the yellow product. The product was filtered and washed with distilled water and recrystallized from ethyl acetate. Drying the product in a vacuum oven at $60^{\circ} \mathrm{C}$ for $4 \mathrm{~h}$ afforded compound 5 with the yield of $5.69 \mathrm{~g}(72.3 \%)$. mp: $136-138^{\circ} \mathrm{C} .{ }^{1} \mathrm{H}$ NMR (dimethyl sulfoxide (DMSO)$\left.d_{6}, \mathrm{ppm}\right): \delta 7.33(\mathrm{~m}, 3 \mathrm{H}, \operatorname{Ar} \mathrm{H}), 7.06(\mathrm{~m}, 3 \mathrm{H}, \mathrm{Ar} \mathrm{H})$, $6.78(\mathrm{~d}, J=16 \mathrm{~Hz}, 1 \mathrm{H}$, vinyl proton $), 6.66(\mathrm{~d}, J=9 \mathrm{~Hz}$, $2 \mathrm{H}$, Ar H) $4.77(\mathrm{t}, J=5 \mathrm{~Hz}, 2 \mathrm{H},-O H), 3.52(\mathrm{t}, J=$ $\left.5 \mathrm{~Hz}, 4 \mathrm{H},-\mathrm{NCH}_{2} \mathrm{CH}_{2} \mathrm{OH}\right), 3.42(\mathrm{t}, J=5 \mathrm{~Hz}, 4 \mathrm{H}$, $-\mathrm{NCH}_{2} \mathrm{CH}_{2} \mathrm{OH}$ ). Anal. Calcd for $\mathrm{C}_{16} \mathrm{H}_{19} \mathrm{NO}_{2} \mathrm{~S}$ : C, $66.40 ; \mathrm{H}, 6.63 ; \mathrm{N}, 4.84 ; \mathrm{S}, 11.08$. Found: C, 66.13; H, $6.53 ; \mathrm{N}, 4.78 ; \mathrm{S}, 11.16$.

\section{Polymer Synthesis}

Poly\{carbonyl[4-(2-(thiophene-2-yl)vinyl $)-N, N-b i s(2-$ oxyethylene $)$ aniline $]$ carbonylimino- $\left(2,2^{\prime}\right.$-dime thoxybiphenylene)imino $\}$ (PU-THP). A $100 \mathrm{~mL}$ two-necked flask containing compound $5(0.5 \mathrm{~g}, 1.73 \mathrm{mmol})$ was connected with a condenser and purged with nitrogen gas for $20 \mathrm{~min}$. To the flask, $15 \mathrm{~mL}$ of distilled DMF and 1 eq of 4,4'-diisocyanato-3,3'-dimethoxydiphenyl $(0.51 \mathrm{~g}$, $1.73 \mathrm{mmol}$ ) were added. The reaction mixture was heated to $c a .80^{\circ} \mathrm{C}$ and kept at this temperature for $12 \mathrm{~h}$. After the solution was allowed to cool to ambient temperature, it was poured into cold water and filtered. The product obtained was washed with water and methanol several times. The yellow product was purified by Soxhlet extraction in methanol for 2 days to give $0.9 \mathrm{~g}$ of the pure product $(89.1 \%) . T_{\mathrm{g}}: 129.2^{\circ} \mathrm{C} .{ }^{1} \mathrm{H}$ NMR (DMSO- $d_{6}$, ppm): $\delta 8.51(\mathrm{~s}, 2 \mathrm{H},-\mathrm{OCONH}-), 7.69(\mathrm{~d}, J=8 \mathrm{~Hz}, 2 \mathrm{H}$, Ar H), $7.35(\mathrm{~m}, 3 \mathrm{H}$, Ar H), 7.21 (m, 4H, Ar H), 7.05 $(\mathrm{m}, 3 \mathrm{H}, \mathrm{Ar} \mathrm{H}), 6.80(\mathrm{~m}, 3 \mathrm{H}, \mathrm{Ar} \mathrm{H}), 4.24(\mathrm{br}, 4 \mathrm{H}$, $\left.-\mathrm{NCH}_{2} \mathrm{CH}_{2} \mathrm{O}-\right), 3.86\left(\mathrm{~s}, 6 \mathrm{H},-\mathrm{OCH}_{3}\right), 3.70(\mathrm{br}, 4 \mathrm{H}$, $\left.-\mathrm{NCH} \mathrm{CH}_{2} \mathrm{O}-\right)$. IR ( $\mathrm{KBr}$ pellet, $\left.\mathrm{cm}^{-1}\right): 3100-3500$ (NH), $1726(\mathrm{C}=\mathrm{O}), 1598$ (Ar CH). Anal. Calcd for $\mathrm{C}_{32} \mathrm{H}_{31} \mathrm{~N}_{3} \mathrm{O}_{6} \mathrm{~S}_{1}$ : C, 65.61; H, 5.35; N, 7.18; S, 5.47. Found: C, 65.63; H, 5.29; N, 7.17; S, 5.28.

Poly $\{$ carbonyl[4-(2-(4-tricyanovinylthiophene-2-yl)vinyl $)-N, N$-bis(2-oxyethylene $)$ aniline $]$ carbonylimino- $\left(2,2^{\prime}\right.$ dimethoxybiphenylene)imino (PU-TCN). To a $100 \mathrm{~mL}$ two-necked flask containing the polymer PU-THP $(0.5 \mathrm{~g}, 0.85 \mathrm{mmol})$ and $15 \mathrm{~mL}$ of anhydrous DMF was added $0.13 \mathrm{~g}(1.01 \mathrm{mmol})$ of tetracyanoethylene. On adding the tetracyanoethylene, the color of the solution rapidly changed to dark green. The reaction mixture was heated at $70^{\circ} \mathrm{C}$ for $12 \mathrm{~h}$ and then cooled to room temperature. The resulting solution was added into methanol dropwise to give a dark green solid. The crude product was filtered and purified by Soxhlet extraction in methanol for 2 days. The polymer yield was $0.56 \mathrm{~g}(96.0 \%) . T_{\mathrm{g}}$ : $175.5^{\circ} \mathrm{C}$. ${ }^{1} \mathrm{H}$ NMR (DMSO- $\left.d_{6}, \mathrm{ppm}\right): \delta 8.50$ (brs, $2 \mathrm{H}$, - OCONH-), 7.96 (br, 1H, Ar H), 7.63 (br d, 2H, Ar H), 7.51 (br, 2H, Ar H), 7.39 (br, 2H, Ar H), 7.20 (br, 5H, $\mathrm{Ar} \mathrm{H}), 6.88$ (br, 2H, Ar H), 4.25 (br, $4 \mathrm{H},-\mathrm{NCH}_{2} \mathrm{CH}_{2} \mathrm{O}-$ ), 
$3.85\left(\mathrm{br}, 10 \mathrm{H},-\mathrm{NCH} \mathrm{CH}_{2} \mathrm{O}-,-\mathrm{OCH}_{3}\right)$. IR ( $\mathrm{KBr}$ pellet, $\left.\mathrm{cm}^{-1}\right): 3100-3500(\mathrm{NH}), 2212(\mathrm{CN}), 1720(\mathrm{C}=\mathrm{O}), 1598$ (Ar CH). UV-Vis (thin film on an ITO-covered glass): $\lambda_{\max }=661.5 \mathrm{~nm}$. Anal. Calcd for $\mathrm{C}_{37} \mathrm{H}_{30} \mathrm{~N}_{6} \mathrm{O}_{6} \mathrm{~S}_{1}$ : C, 64.70; H, 4.41; N, 12.24; S, 4.67. Found: C, 64.94; $\mathrm{H}, 4.48 ; \mathrm{N}, 12.38 ; \mathrm{S}, 4.58$.

\section{Measurements}

${ }^{1} \mathrm{H}$ NMR and ${ }^{13} \mathrm{C}$ NMR spectra were recorded on Bruker AM 200 and AM 300 spectrometers. FT-IR spectra were obtained with a Bomem Michelson series FT-IR spectrometer and UV-Vis absorption spectra were measured on a Shimadzu UV-3100S spectrophotometer. Differential scanning calorimetry (DSC) and thermogravimetric analysis (TGA) were performed under nitrogen atmosphere at a heating rate of $10^{\circ} \mathrm{C} \mathrm{min}^{-1}$ on a Dupont 2100 analyzer. The number average molecular weight $\left(M_{n}\right)$ and weight average molecular weight $\left(M_{w}\right)$ of the polymers were estimated by gel permeation chromatography (GPC) (columns styragel HR5E4E2; solvent THF). The film thickness was determined using the Tencor alpha-step 500 surface profiler.

\section{Film Preparation and SHG Measurements}

PU-TCN showed considerable solubility in aprotic polar organic solvents such as DMF, $N$-methylpyrrolidinone (NMP), etc. The best optical quality film was obtained from a $5 \%$ (by weight) polymer solution in NMP. Prior to film casting the polymer solution was filtered through a $0.45 \mu \mathrm{m}$ Teflon membrane filter (Aldrich). However, after spin casting at room temperature, the turbid film was obtained due to relatively low solubility. So we used a special technique in the film preparation. To increase the solubility of the polymer, the ITO-covered glasses and the polymer solution were heated at $c a .100^{\circ} \mathrm{C}$ for about $10 \mathrm{~min}$ before film casting. As a result of using hot ITO glasses and a hot solution, yielded the film of better optical quality. The PU-TCN film was obtained by spin cast with hot substrates and the hot polymer solution at a rate of $1500 \mathrm{rpm}$ from the $5 \mathrm{wt} \%$ NMP solution. The film was dried for $6 \mathrm{~h}$ under reduced pressure at $120^{\circ} \mathrm{C}$ to drive out the residual solvents. This solvent-free film was used in the poling process under a DC electric field. To further align the dipole moment of the NLO chromophore, the film was electrically poled in a Corona-discharge set-up. The poling was performed in a wire-to-plane geometry. The discharging wire to plane distance was $1.0 \mathrm{~cm}$ and the temperature was gradually increased at a rate of $10^{\circ} \mathrm{C} \mathrm{min}^{-1}$ from room temperature to the temperature near the glass transition: $5.3 \mathrm{kV}$, at $182^{\circ} \mathrm{C}$ for $20 \mathrm{~min}$. The sample was cooled to room temperature in the presence of a poling electric field.

The second harmonic generation (SHG) experiments $^{21,22}$ were performed with a $p$-polarized beam at the fundamental frequency of a mode-locked Q-switched $\mathrm{Nd}$ :YAG laser (Lumonics HY750) operating at $10 \mathrm{~Hz}$ with $8 \mathrm{~ns}$ subpulses in each pulse train. The IR laser light passed through an attenuator, a half wave-plate, and a polarizer was incident to the side of the film surface on the ITO glass. A second harmonic light from a sample was passed through a band-pass filter to remove a fundamental wave. The SHG signals from $p$-polarizer were accumulated on a photomultiplier tube (Hamamatsu R-928) and averaged with a Boxcar averager (Stanford SRS250) to increase the signal to noise ratio. The Maker Fringe pattern was obtained from measuring the SHG signal at $0.5^{\circ}$ intervals using a rotation stage (Micro-controle TL78). The reference used is a $4.65 \mathrm{~mm}$ thick, Y-cut quartz plate with a second-order nonlinearity of $d_{11}=0.5 \mathrm{pm} \mathrm{V}^{-1}$.

The SHG coefficient of the film was calculated using the method developed by Herman et al. in which both the absorption and birefringence of the sample film as well as reflections were considered. ${ }^{23}$

By writing the complex index of refraction as $\tilde{n}_{m}=n_{m}\left(1+i \kappa_{m}\right)$, where $\kappa_{m}$ is the extinction coefficient of the nonlinear material at frequency $m \omega$, the SHG intensity from an absorbing material is expressed by following equation.

$$
\begin{aligned}
P_{2 \omega}^{r \rightarrow p}= & \frac{128 \pi^{3}}{c A} \frac{\left|t_{\mathrm{af}}^{1 \gamma}\right|^{4}\left|t_{\mathrm{fs}}^{2 p}\right|^{2}\left|t_{\mathrm{sa}}^{2 p}\right|^{2}}{n_{2}^{2} c_{2}^{2}} \\
& \times P_{\omega}^{2}\left(\frac{2 \pi L}{\lambda}\right)^{2} d_{\mathrm{eff}}^{2} \exp \left\{-2\left(\delta_{1}+\delta_{2}\right)\right] \\
& \times \frac{\sin ^{2} \Psi+\sinh ^{2} \chi}{\Psi^{2}+\chi^{2}}
\end{aligned}
$$

where

$$
\begin{aligned}
\Psi & =(2 \pi L / \lambda)\left(n_{1} c_{1}-n_{2} c_{2}\right) \\
\delta_{1} & =(2 \pi L / \lambda)\left(n_{1} \kappa_{1} / c_{1}\right) \\
\delta_{2} & =(2 \pi L / \lambda)\left(n_{2} \kappa_{2} / c_{2}\right) \\
\chi & =\delta_{1}-\delta_{2}=(2 \pi L / \lambda)\left(n_{1} \kappa_{1} / c_{1}-n_{2} \kappa_{2} / c_{2}\right) \\
t_{\mathrm{af}}^{1 \gamma} & =\frac{2 \cos \theta}{c_{1}+n_{1} \cos \theta}, \text { for } p \text {-polarized incident light } \\
t_{\mathrm{af}}^{1 \gamma} & =\frac{2 \cos \theta}{\cos \theta+n_{1} c_{1}}, \text { for } s \text {-polarized incident light } \\
t_{\mathrm{fs}}^{2 p} & =\frac{2 n_{2} c_{2}}{n_{2 s} c_{2}+n_{2} c_{2 s}}, \\
t_{\mathrm{sa}}^{2 p} & =-\frac{2 n_{2 s} c_{2 s}}{n_{2 s} \cos \theta+c_{2 s}}
\end{aligned}
$$

where $\theta$ is the incident angle; $P_{\omega}$, the intensity of the fundamental light $(1064 \mathrm{~nm}) ; \lambda$, the wavelength of the fundamental beam; $A$, the area of incident light; $c$, velocity of the light

The terms of $t_{\mathrm{af}}, t_{\mathrm{fs}}$, and $t_{\mathrm{sa}}$ are the transmission coefficients from air to film, film to substrate, and substrate to air, respectively. The subscripts 1 and 2 are the fundamental and SHG light, respectively. The terms, $s_{m}$ and $c_{m}$ are defined as follows.

$$
\begin{aligned}
& s_{m}=\left(1 / n_{m}\right) \sin \theta \\
& c_{m}=\sqrt{1-s_{m}^{2}}
\end{aligned}
$$

In addition, from the Snell's law,

$$
\sin \theta=n_{1} \sin \theta_{1}=n_{2} \sin \theta_{2}=n_{2 s} \sin \theta_{2 s}
$$

In the case of NLO materials with $c_{\infty \mathrm{v}}$ symmetry, 


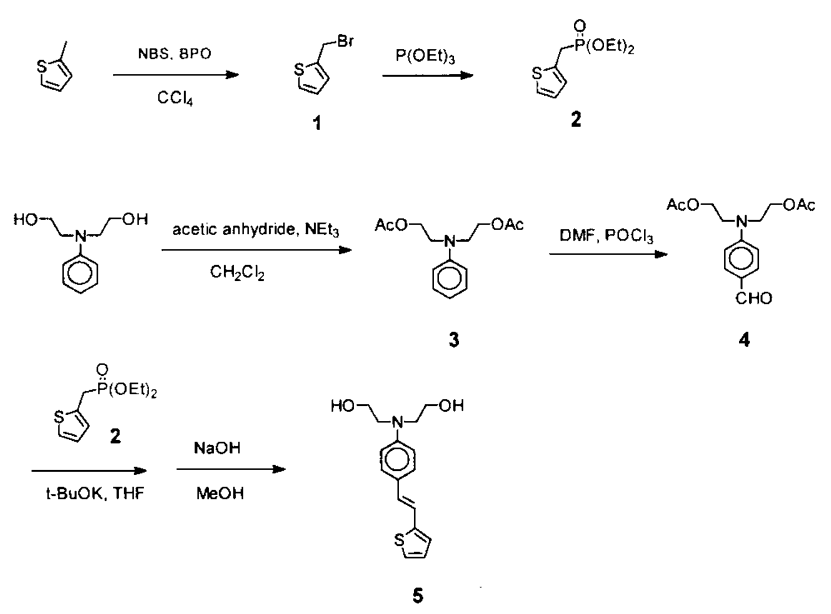

Scheme 1.

$d_{\text {eff }}=2 d_{31} c_{1} s_{1} c_{2}+d_{31} c_{1}^{2} s_{2}+d_{33} s_{1}^{2} s_{2}$, for $p$-polarized incident light

$$
d_{\text {eff }}=d_{31} s_{2} \text { for } s \text {-polarized incident light }
$$

Finally we can deduce $d_{31}$ and $d_{33}$ values from $d_{\text {eff }}$ in the above equations.

\section{RESULTS AND DISCUSSION}

\section{Synthesis and Characterization}

The synthetic routes for the monomer and the final polyurethane are presented in Scheme 1 and 2. 2Methylthiophene was brominated and then further reacted with triethylphosphite to yield the phosphonate compound 2. Compound 1 must be immediately reacted after distillation because of the fast deterioration. Phosphonate 2 was relatively stable, and was preserved in a refrigerator without any change in quality. The $N, N$-bis(2-hydroxyethyl)aminobenzene was protected with acetic anhydride and followed by successive Villsmeier formylation in a DMF solvent, yielding compound 4. A subsequent reaction of 4 and phosphonate $\mathbf{2}$ in Horner-Emmons Wittig condition gave a diol monomer 5. All intermediates, including the monomer, were characterized by common spectroscopic techniques such as ${ }^{1} \mathrm{H}$ NMR, IR, UV-Vis, and elemental analysis. Their results are in good agreement with the structures obtained in each stage of the synthetic route.

The prepolymer, PU-THP, was synthesized by condensation polymerization between a diol monomer 5 and diisocyanate, 4,4'-diisocyanato-3,3'-dimethoxydiphenyl, in an anhydrous DMF solvent. The polymerization yield was $89 \%$. The PU-THP was quite soluble in common organic solvents such as THF, DMF, and cyclohexanone. In order to afford second-order optical nonlinearity to this polymer, the PU-THP was tricyanovinylated with tetracyanoethylene in anhydrous DMF. By adding 1.2 eq. of tetracyanoethylene relative to PU-THP, all of the chromophores in the polymer backbone were functionalized, which was confirmed by FT-IR, UV-Vis, ${ }^{1} \mathrm{H}$ NMR spectroscopy and elemental analysis. Because HCN gas is evolved during the reaction, much care is needed. The final polyurethane, PU-TCN, was purified by Soxhlet extraction in methanol for 2 days. The resulting polymer was a dark green powder
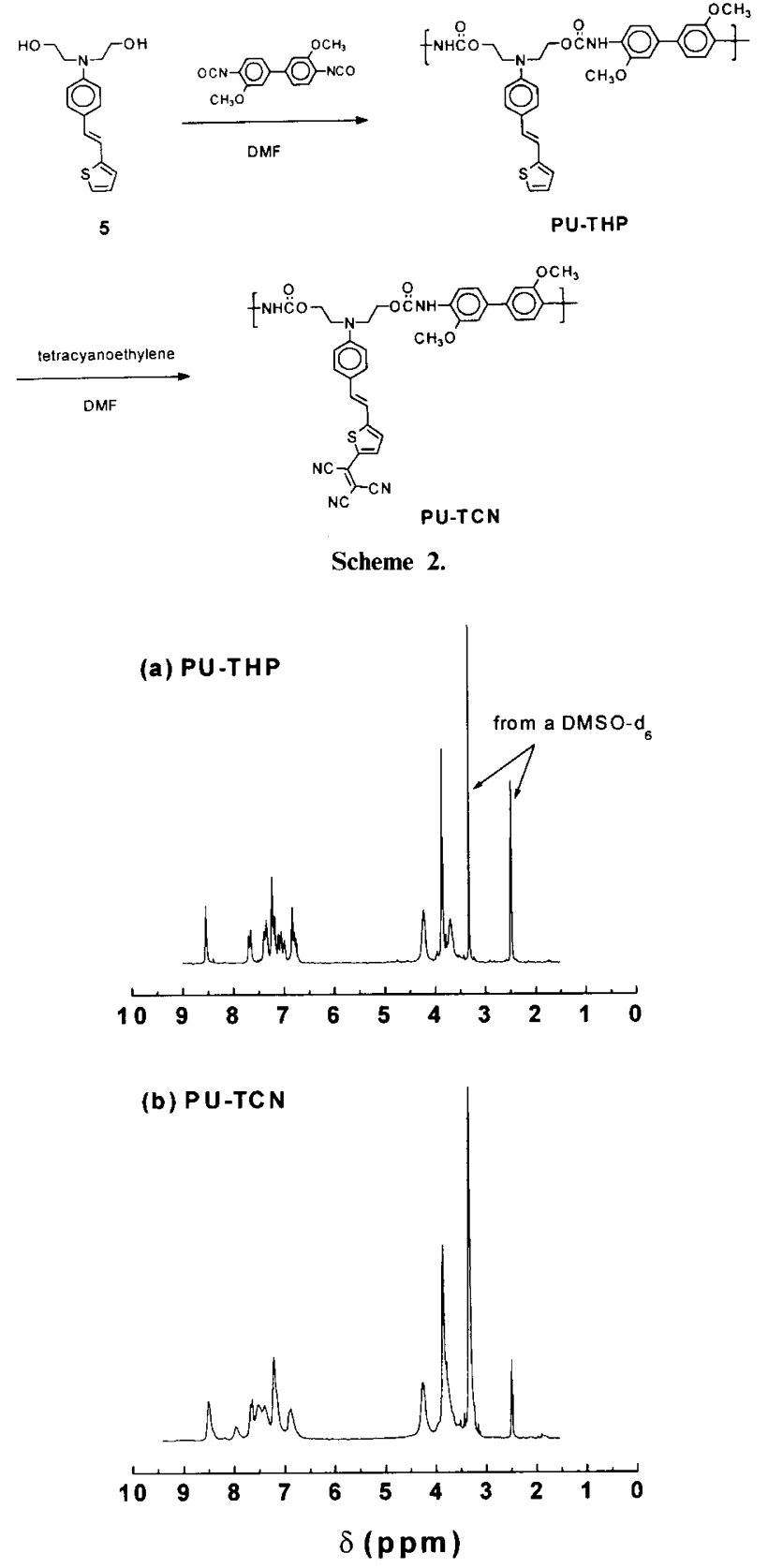

Figure 1. ${ }^{1} \mathrm{H}$ NMR spectra of (a) PU-THP and (b) PU-TCN in DMSO- $d_{6}$.

and stable in air.

The number average molecular weights of the polymers were determined to be $11900\left(M_{w} / M_{n}=1.99\right)$ for PU-THP and $12000\left(M_{w} / M_{n}=2.04\right)$ for PU-TCN, respectively. The final polyurethane, PU-TCN, was soluble in aprotic polar solvents such as DMF, NMP, etc. The solubility of PU-TCN was drastically decreased relative to PU-THP, which is ascribed to the increased rigidity after tricyanovinylation. Figure 1 shows the ${ }^{1} \mathrm{H}$ NMR spectra of the polymers, which shows a signal broadening due to polymerization, but the chemical shifts are quite consistent with the proposed polymer structures. In both cases, the line at $8.5 \mathrm{ppm}$ assigned to the amine proton indicates the formation of urethane linkage. The peak at $2.5 \mathrm{ppm}$ comes from DMSO- $d_{6}$ and the line at $3.3 \mathrm{ppm}$ originates from $\mathrm{H}_{2} \mathrm{O}$ molecules in solvents. After tricyanovinylation, the peak at $7.9 \mathrm{ppm}$, 


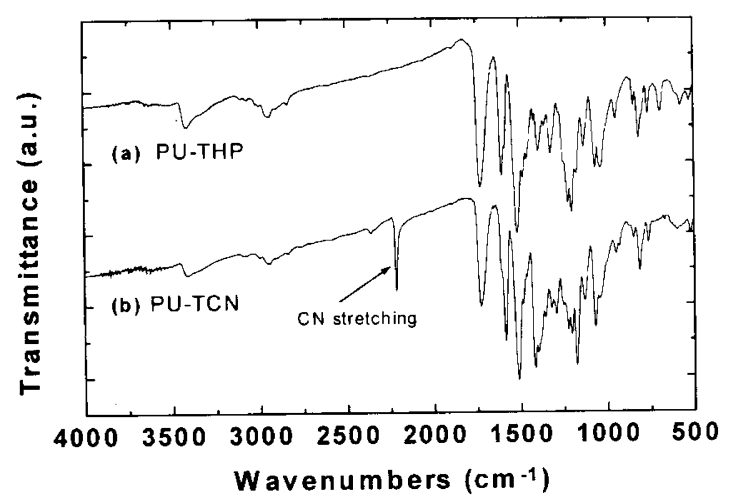

Figure 2. FT-IR spectra of the resulting polymers (a) PU-THP and (b) PU-TCN with $\mathrm{KBr}$ pellets.

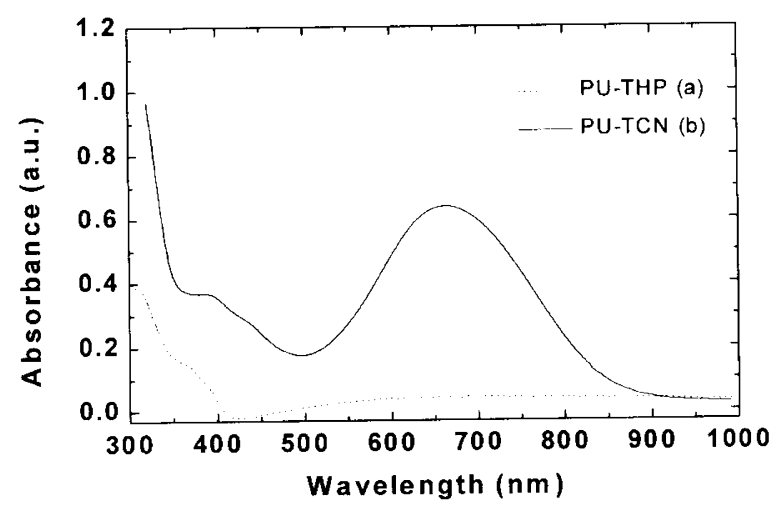

Figure 3. UV-Vis absorption spectra of two polyurethane solutions in DMF (a) PU-THP and (b) after tricyanovinylation, new strong absorption at $659.5 \mathrm{~nm}$ was observed in PU-TCN.

which is ascribed to the hydrogen near the tricyanovinyl functionality was down field shifted from around $7.0 \mathrm{ppm}$ owing to strong electron-withdrawing ability of substituted tricyanovinyl group. The FT-IR spectra of the polyurethanes also show the formation of urethane bonds (Figure 2). In both of PU-THP and PU-TCN, the strong peak at $1720 \mathrm{~cm}^{-1}$ is due to the carbonyl stretching in the urethane linkage. However, after tricyanovinylation, the new sharp peak at $2212 \mathrm{~cm}^{-1}$ appeared and it came from $-\mathrm{CN}$ stretching in the NLO chromophore, from which, it is known that the tricyanovinylation was successfully completed. This result matched well with the UV-Vis spectra (DMF solutions) shown in Figure 3. A new strong absorption at $659.5 \mathrm{~nm}$ in PU-TCN, which is not observed in PU-THP, indicates that NLO chromophore is generated by tricyanovinylation. This new absorption at longer wavelength was originated from the $\pi-\pi^{*}$ transition of the extended conjugation covering from the benzene ring to the tricyanovinyl group. In addition, the absorption at $366.5 \mathrm{~nm}$ by the thiophene chromophore without tricyanovinylation was drastically diminished and it is due to the unreacted portion but the amount of which is very small. We confirmed that almost all of the chromophores were functionalized from elemental analysis.

The thermal characterizations of the polyurethanes were carried out by using TGA and DSC. The TGA studies indicated that the initial decay of the system started at $c a .289^{\circ} \mathrm{C}$ for PU-THP and $266^{\circ} \mathrm{C}$ for PU-TCN under a nitrogen atmosphere (Figure 4). The weight loss

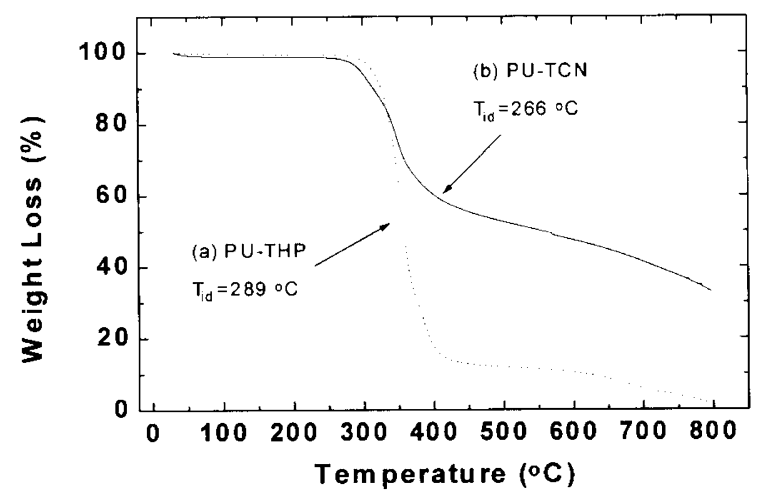

Figure 4. TGA traces of two polyurethanes PU-THP and PU-TCN with heating rate $10^{\circ} \mathrm{C} \mathrm{min}^{-1}$ under nitrogen atmosphere.

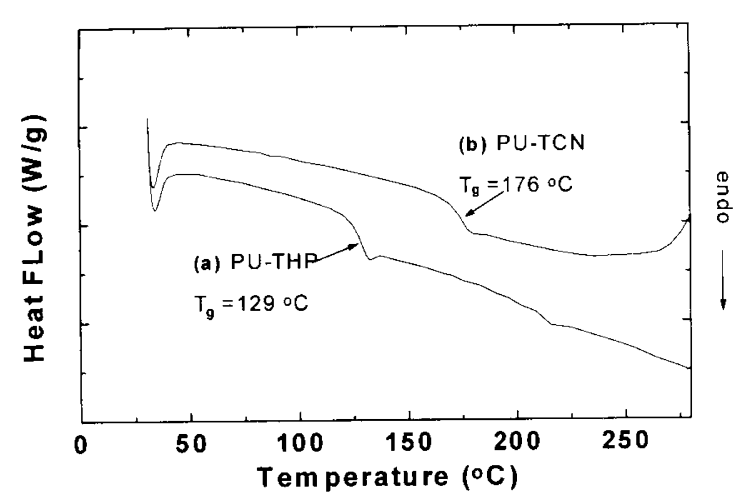

Figure 5. DSC diagrams of the polymers with a heating rate of $10^{\circ} \mathrm{C} \mathrm{min}^{-1}$ under a nitrogen atmosphere.

of tricyanovinylated PU-TCN is retarded relative to PU-THP at higher temperature regions (over $400^{\circ} \mathrm{C}$ ), and this may be explained by increased rigidity by way of the formation of a charge-transfer complex between electron-donor and acceptor groups in the tricyanovinylated chromophores. PU-TCN has a high polarizability due to the tricyanovinyl group's electron accepting effect. Hence, the thermal stability shown by PU-TCN may be attributed to the attractive interaction between the nonbonding electrons of thiophene and the strongly electron-attracting tricyanovinyl group, which gives chain rigidity and thus retarded the weight loss at higher temperatures. ${ }^{6}$ Futher work is needed to confirm this hypothesis. A DSC thermogram was obtained after annealing the sample at $200^{\circ} \mathrm{C}$ for $30 \mathrm{~min}$ under nitrogen. A glass transition temperature $\left(T_{\mathrm{g}}\right)$ of $c a .129^{\circ} \mathrm{C}$ was observed for PU-THP in DSC analysis (Figure 5). After tricyanovinylation, the glass transition occurred at a much higher temperature, $c a .176^{\circ} \mathrm{C}$ for PU-TCN. The $T_{\mathrm{g}}$ of PU-TCN is $47^{\circ} \mathrm{C}$ higher than that of pre-polymer, PU-THP. This may be ascribed to the increased rigidity of the system after NLO-functionalization, accompanying decreased solubility and processibility. In the DSC thermograms, no melting point was detected, indicating that they represent a noncrystalline phase.

\section{Second-Order Nonlinear Properties}

SHG measurements were performed at a fundamental wavelength of $1064 \mathrm{~nm}$ using a mode-locked Nd:YAG laser. ${ }^{21-23}$ The final polyurethane, PU-TCN, was readily soluble in NMP and could be processed into a good 


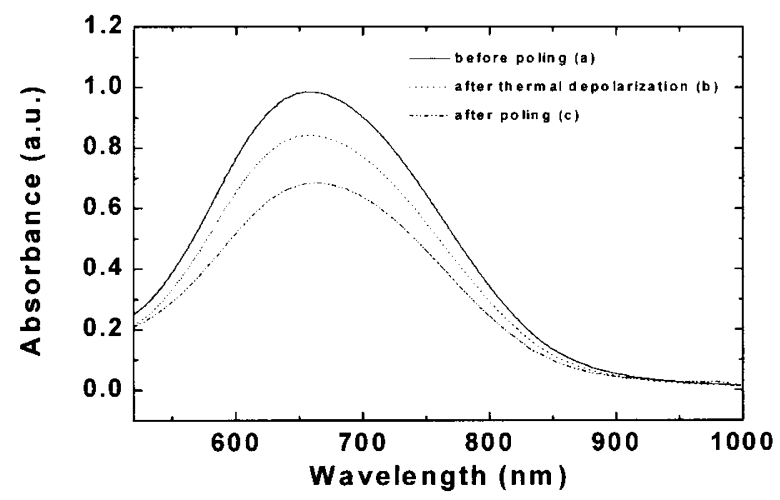

Figure 6. UV-Vis absorption change of a PU-TCN film on an ITO-covered substrate (a) before poling, (b) after thermal depolarization, and (c) after poling.

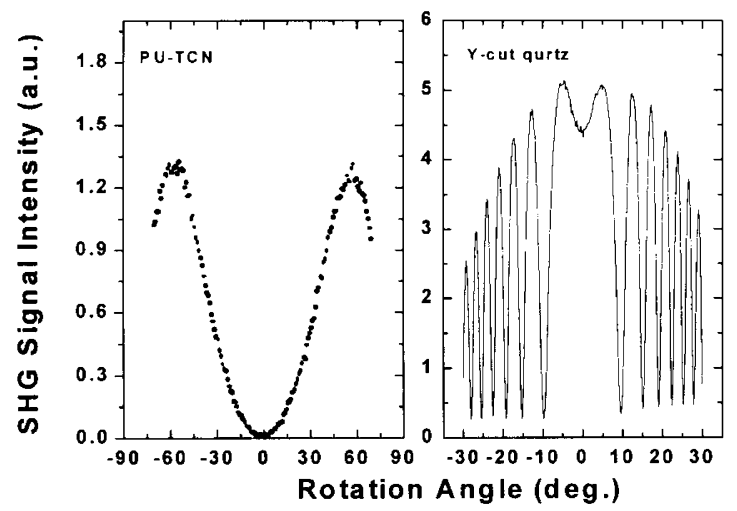

Figure 7. Angular dependence of SHG signal in a poled PU-TCN film and that of a $4.65 \mathrm{~mm}$-thick Y-cut quartz plate.

optical quality film by spin casting at $c a .100^{\circ} \mathrm{C}$. To induce the second-order optical nonlinearity, the polymer film was poled at around $T_{\mathrm{g}}$ for about $20 \mathrm{~min}$ and cooled to room temperature. The electronic absorption spectra of the sample before and after the poling process are presented in Figure 6. After the electric poling, the dipole moments of the NLO chromophores were aligned and the UV-Vis spectrum of PU-TCN exhibited a decrease in absorption due to birefringence. From the absorbance change, the order parameter of the poled film could be estimated, which is related to the poling efficiency. The estimated order parameter value, $\Phi$, was deduced to be $0.31\left(\Phi=1-A_{1} / A_{0}, A_{0}\right.$ and $A_{1}$ are the absorbances of the polymer film before and after corona poling). Figure 6(b) shows the recovered UV-Vis absorption after undergoing thermal relaxation of the aligned dipoles. The reason for the incomplete recovery back to its original absorption intensity may be due to partial destruction of the chromophores during the harsh poling process. The corresponding polymer film, which was thermally treated without poling field at $200^{\circ} \mathrm{C}$ for $1 \mathrm{~h}$ under nitrogen, showed no change in the absorption spectrum. This indicates that the NLO chromophore can survive in that temperature range for a short time in the absence of a poling electric field.

In order to determine the macroscopic second-order susceptibility of the material, the angular SHG dependence was recorded and then compared with the values obtained from a $4.65 \mathrm{~mm}$ thick, Y-cut quartz plate (Figure 7). The measurements were taken after the poled

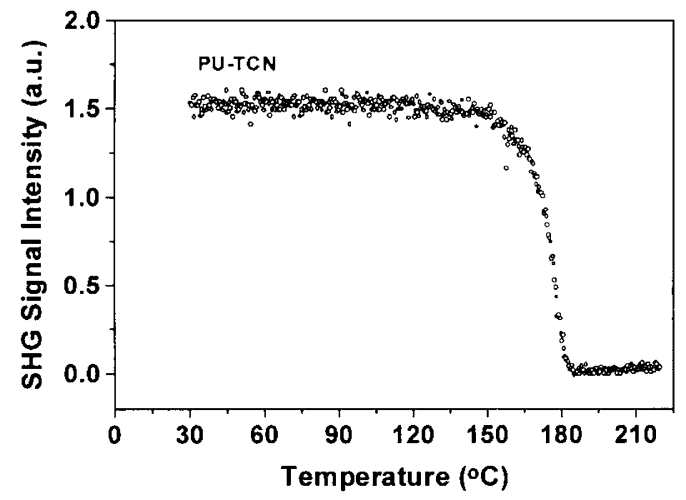

Figure 8. Thermal endurance of the aligned dipoles in poled PU-TCN.

film was left at room temperature overnight to remove the residue charge caused by the poling field. The SHG coefficient, $d_{33}$, was calculated through the method developed by Herman et al., in which the absorption and birefringence of the film sample including reflections were considered. ${ }^{23}$ If a certain amount of absorption exists in the second harmonic region, this leads to significant errors in the effective second harmonic $d$ coefficient. Because our polyurethane film sample has small but non-negligible absorption at $532 \mathrm{~nm}$, this absorption must be considered in calculating the SHG coefficient of the film. The estimated absorption coefficient, $\alpha_{2 \omega}^{f}$ of the film at the second harmonic wavelength from UV-Vis absorption was $2.22 \mu \mathrm{m}^{-1}$. In the calculation of $d_{\mathrm{eff}}$, the isotropic model approximation of $d_{33} \cong 3 d_{31}$ was used. $^{23}$ The SHG measurement revealed a large $d_{33}$ value of $51 \mathrm{pm} \mathrm{V}^{-1}$ for PU-TCN (the assumed refractive index values ( $n_{1}=1.62$ at $1064 \mathrm{~nm}, n_{2}=1.78$ at $532 \mathrm{~nm}$ ) were used). Since the second harmonic wavelength was at $532 \mathrm{~nm}$, which is in the absorptive region of the resulting polyurethane, there was a non-negligible resonant contribution to this $d_{33}$ value.

The thermal stability of the second harmonic signal was studied by monitoring the SHG signals as a function of temperature (at an increasing rate of $5^{\circ} \mathrm{C} \mathrm{min}^{-1}$ from $30^{\circ} \mathrm{C}$ until $220^{\circ} \mathrm{C}$ ). The results are shown in Figure 8. The SHG signal exhibited no decay until ca. $150^{\circ} \mathrm{C}$. When the temperature reached above $155^{\circ} \mathrm{C}$, a fast signal decay set in, causing the SHG signal to disappear within 10 min. When our system is compared with other systems which do not have hydrogen bonds, such as poly(methyl methacrylate), polystyrene, or poly(phenylenevinylene)based NLO polymers, better stability of the aligned dipoles was obtained. ${ }^{24-26}$ As we pointed out at the beginning, this improved thermal stability may be ascribed to the extensive formation of hydrogen bridges between neighboring polyurethane chains which, in turn, is likely to increase the matrix rigidity. Since our system was proved to be completely amorphous in the DSC analysis, it is expected that more free inter-chain hydrogen bonds take place because of the high entropy conformation of the backbone. Hydrogen bridges in polyurethane, polyamide, polypeptide, etc. are well known and documented. ${ }^{9,27-30}$ This depoling process was irreversible and the SHG signal did not recover when the sample was brought back to room temperature. 


\section{CONCLUSIONS}

A new NLO-functionalized polyurethane with a highly nonlinear heteroaromatic thiophene chromophore having a tricyanovinyl group was synthesized and characterized. Heteroaromatics such as thiophene are expected to exhibit high nonlinear activity due to the lower delocalization energy relative to the benzene derivatives. It showed high second-order nonlinearity with a SHG coefficient, $d_{33}=51 \mathrm{pm} \mathrm{V}^{-1}$. In addition, the high thermal stability of the aligned dipoles was observed up to $150^{\circ} \mathrm{C}$ without any measurable decay. This good stability can be originated from the polymer backbone rigidity caused by the effective inter-chain hydrogen bridges between neighboring the polyurethane chains.

Acknowledgments. We gratefully acknowledge the financial support of the Korea Science \& Engineering Foundation (KOSEF). We gratefully thank Dr. Y. H. Min (KAIST) and Dr. M. Y. Jin (KRICT) for their help in measuring the SHG activities of our sample.

\section{REFERENCES}

1. P. N. Prasad and D. J Williams, "Introduction to Nonlinear Effects in Monomers and Polymers," John Wiley \& Sons, New York, N.Y., 1991

2. D. J. Williams, Angew. Chem. Int. Ed. Engl., 23, 690 (1984)

3. R. D. Miller, D. M. Burland, M. Jurich, V. Y. Lee, C. R. Moylan, J. I. Thackara, R. J. Twieg, T. Verbiest, and W. Volksen, Macromolecules, 28, 4970 (1995).

4. H. Saadeh, A. Gharavi, D.Yu, and L.Yu, Macromolecules, 30 , 5403 (1997)

5. D. Yu, A. Gharavi, and L.Yu, J. Am. Chem. Soc., 117, 11680 (1995)

6. K.-S. Lee, K.-J. Moon, H. Y. Woo, and H.-K. Shim, Adv. Mater. 9, 978 (1997)

7. H. Y. Woo, K.-J. Moon, H.-K. Shim, K.-S. Lee, M.-Y. Jeong, and T.-K. Lim, Chem. Mater., 11, 218 (1999).

8. N. P. Wang, T. M. Leslie, S. Wang, and S. T. Kowel, Chem.
Mater., 7, 185 (1995).

9. K.-J. Moon, H.-K. Shim, K.-S. Lee, J. Zieba, and P. N. Prasad, Macromolecules, 29, 861 (1996).

10. C. Xu, B. Wu, L. R. Dalton, Y. Shi, P. M. Ranon, and W. H. Steier, Macromolecules, 25, 6714 (1992).

11. B. K. Mandal, Y. M. Chen, J. Y. Lee, J. Kumar, and S. Tripathy, Appl. Phys. Lett., 58, 2459 (1991).

12. K.-S. Lee, S.-W. Choi, H. Y. Woo, K.-J. Moon, H.-K. Shim, M.-Y. Jeong, and T.-K. Lim, J. Opt. Soc. Am. B, 15, 393 (1998).

13. K. D. Singer, J. E. Sohn, L. A King, H. M. Gordon, H. E. Katz, and C. W. Dirk, J. Opt. Soc. Am. B, 6, 1339 (1989).

14. L. T. Cheng, W. Tam, S. R. Marder, A. E. Stiegman, G. Rikken, and C. W. Spangler, J. Phys. Chem., 95, 10643 (1991).

15. L. T. Cheng, W. Tam, S. H. Stevenson, G. R. Meredith, G. Rikken, and S. R. Marder, J. Phys. Chem., 95, 10631 (1991).

16. A. E. Stiegman, E. Graham, K. J. Perry, L. R. Khundkar, L. T. Chang, and J. W. Perry, J. Am. Chem. Soc., 113, 7568 (1991).

17. V.P. Rao, A. K.-Y. Jen, K. Y. Wong, and K. J. Drost, Tetrahedron Lett., 34, 1747 (1993).

18. (a) A. K.-Y. Jen, V. P. Rao, K. Y. Wong, and K. J. Drost, J. Chem. Soc., Chem. Commun., 90 (1993). (b) V: P. Rao, A. K.-Y. Jen, K. Y. Wong, and K. J. Drost, J. Chem. Soc., Chem. Commun., 1118 (1993).

19. V. P. Rao, K. Y. Wong, A. K.-Y. Jen, and K. J. Drost, Chem. Mater., 6, 2210 (1994).

20. G. W. Wheland, "Resonance in Organic Chemistry," John Wiley \& Sons, New York, N.Y., 1955, p 99.

21. P. D. Maker, R. W. Terhune, M. Nisenoff, and C. M. Savage, Phys. Rev. Lett., 8, 21 (1962)

22. J. Jerphagnon and S. K. Kurtz, J. Appl. Phys., 40, 1667 (1970).

23. W. N. Herman and L. M. Hayden, J. Opt. Soc. Am. B, 12, 416 (1995).

24. C. Ye, T. J. Marks, J. Yang, and G. K. Wong, Macromolecules, 20, 2322 (1987).

25. M. Yoshida, M. Asano, M. Tamada, and M. Kumakura, Makromol. Chem., Rapid Commun., 10, 517 (1989).

26. C. B. Yoon, K.-J. Moon, and H.-K. Shim, Macromolecules, 29, 5754 (1996)

27. S. B. Lin, K. S. Hwang, S. Y. Tsay, and S. L. Cooper, Colloid Polym. Sci., 263, 128 (1985).

28. R. Bonart, J. Macromol. Sci. Phys., B2, 115 (1968).

29. R. B. Seymour, "Polymer Chemistry," 2nd ed, Marcel Dekker, New York, N.Y., 1988, p 175

30. Y. M. Chen, Z. H. Peng, W. K. Chan, and L. P. Yu, Appl. Phys. Lett., 64, 1195 (1994). 